\title{
Crónica de la jornada sobre el empleo de las personas con discapacidad, celebrada el día 7 de noviembre de 2019
}

\author{
Cronaca della giornata sull'occupazione delle persone \\ con disabilità, tenutasi il 7 novembre 2019
}

\author{
DAVID GutiÉRREZ COLOMINAS \\ Investigador Postdoctoral (acreditado profesor \\ contratado doctor) \\ Universidad Autónoma de Barcelona \\ ORCID: https://orcid.org/0000-0001-9845-9917
}

Recibido: $11 / 11 / 2019$

Aceptado: $13 / 11 / 2019$

doi: https://doi.org/10.20318/femeris.2020.5162

La igualdad y no discriminación en el empleo es una temática de creciente interés, que ha adquirido una importancia crucial en los últimos años. Como consecuencia de ello, la Asociación Española del Derecho del Trabajo y de la Seguridad Social (AEDTSS) creó la Comisión de igualdad, que nació con la vocación de desarrollar una actuación de defensa de los derechos a la igualdad y a la no discriminación en el ámbito de las relaciones laborales

En este sentido, es objetivo de la comisión de igualdad la organización anual de un acto dedicado a alguna o diversas causas de discriminación plasmadas en la Directiva 2000/78/CE del Consejo, de 27 de noviembre de 2000, relativa al establecimiento de un marco general para la igualdad de trato en el empleo y la ocupación (Directiva 2000/78/ CE), y este año el protagonismo lo ha asumido la discapacidad. En efecto, esta causa de no discriminación se halla entre las previstas en el artículo 1 De la Directiva 2000/78/CE, y ha adquirido una importancia central en los últimos tiempos como consecuencia de distintas sentencias del Tribunal de Justicia de la Unión Europea.

Ante esta situación, la comisión de igualdad de la AEDTSS decidió centrar las primeras jornadas precisamente en distintos aspectos conflictivos de esta causa de no discriminación, que se han materializado en la celebración de la jornada objeto de crónica el pasado día 7 de noviembre de 2019 en el Campus "Puerta de Toledo" de la Universidad Carlos III en Madrid.

*david.gutierrez@uab.cat 
Las temáticas de la jornada han sido sumamente diversas, y han alcanzado el tratamiento de aspectos estructurales del empleo de las personas con discapacidad, el régimen jurídico del deber de realizar ajustes razonables en el puesto de trabajo, discapacidad y género, el cumplimiento de la cuota de reserva de empleo, y el tratamiento de cuestiones relacionadas con las extinciones de las personas con discapacidad, abordadas desde la perspectiva de los despidos no causales en el marco de situaciones de incapacidad temporal y las extinciones del contrato de trabajo vinculadas a la discapacidad.

El acto se inició con la intervención inicial del Ilmo. Sr. José Fernando Lousada Arochena (Copresidente de la Comisión de igualdad de la AEDTSS) que, tras los correspondientes agradecimientos a las distintas entidades que han colaborado en la organización del evento, destacó la importancia de la cuestión desde distintos puntos de vista. Concretamente, puso el acento en la evolución asistencial de la normativa y los distintos documentos internacionales existentes, destacando las implicaciones y aportaciones que efectúo la Convención Internacional de los Derechos de las Personas con Discapacidad (CIDPD). En particular, destacó la transición de un modelo individual de tratamiento de la discapacidad, centrado en las necesidades individuales de las personas, hacia un modelo social de tratamiento de la discapacidad, en el que la prioridad es eliminar las barreras. Precisamente la CIDPD es tributaria de este paradigma, y asume un lenguaje de derechos, que pretende favorecer una inclusión efectiva de este colectivo.

A continuación dedicó unas palabras de bienvenida el Sr. Jesús Ángel Celada Pérez (Director General de Políticas de discapacidad - Ministerio de Sanidad, Consumo y Bienestar Social), que ofreció algunas reflexiones a propósito de las necesidades de este colectivo, destacando el momento histórico que está viviendo esta temática, debido a la próxima modificación del artículo 49 de la Constitución Española, la posibilidad de ejercitar el derecho a voto de las personas con discapacidad y la modificación de la figura de la tutela, contenida en el Código Civil, a fin de empoderar a las personas con discapacidad mediante la aplicación de instituciones más flexibles, como, por ejemplo, la curatela.

Por último, el gerente de la AEDTSS, el Prof. Barrios Baudor (URJC), finalizó la inauguración de la jornada excusando la presencia de la profesora Casas Baamonde, que no pudo asistir a la jornada como consecuencia de su nombramiento como doctora honoris causa en la Universidad de Las Palmas de Gran Canaria, y continuó a través diversos agradecimientos a los distintos organismos que colaboraron en la organización de las jornadas, así como a los asistentes/as.

El inicio del primer panel, moderado por la profesora Quintanilla Navarro (UCM), arrancó con la ponencia que realizó el profesor Esteban Legarreta (UAB), que bajo el título "Algunos aspectos estructurales en torno a la regulación del empleo de las personas con discapacidad", abordó aspectos diversos del empleo de las personas con discapacidad. Partiendo de que la discapacidad significa la necesidad de actuaciones diversas en necesidades de atención, el prof. Esteban inició su ponencia mediante un análisis crítico del marco jurídico español, con especial atención al Real Decreto Legislativo 1/2013, de 29 de noviembre, por el que se aprueba el Texto Refundido de la Ley General de derechos de las personas con discapacidad y de su inclusión social (LGDPCD). Su exposición continuó 
destacando la desaparición del principio de preferencia para el empleo ordinario, y destacando el escaso número de iniciativas de reforma de la normativa, como consecuencia de la falta de intervención de los principales actores en el ordenamiento jurídico laboral (sindicatos y organizaciones empresariales). Por último, la ponencia abordó tres reflexiones elementales, referidas al concepto de persona con discapacidad, la conveniencia de la puesta en marcha de planes de igualdad y la consolidación de mejora del empleo con apoyo, que apuntaban a la necesidad de actualizar el actual marco jurídico mediante una reforma urgente de las cuestiones mencionadas.

En segundo lugar, intervino la Prof. Rodríguez Sanz de Galdeano (UPNA), que, tras los oportunos agradecimientos, inició su intervención titulada "El deber de introducir adaptaciones como medida de acceso y de mantenimiento del empleo de las personas con discapacidad". La ponente destacó el papel central de los ajustes razonables como medida más representativa del modelo social de tratamiento de la discapacidad, que aboga por la transformación de los entornos para lograr la igualdad de oportunidades. Estructuralmente, su ponencia abordó reflexiones a propósito del concepto de persona con discapacidad, el alcance de la obligación y el contenido de las medidas de ajustes, que fueron previamente introducidas con un exhaustivo examen del marco jurídico de aplicación. A propósito del concepto de persona con discapacidad, la prof. Rodríguez señaló los problemas que plantea la falta de definición del concepto "discapacidad" en la directiva, complementando su explicación con la doctrina dictada por el Tribunal de Justicia de la Unión Europea en la materia. Sobre el alcance de la obligación, la ponente destacó la ambigüedad de la razonabilidad exigida a los ajustes y la carga excesiva, clarificando que la razonabilidad se refiere a la eficacia y/o viabilidad y la carga excesiva apunte a los límites de la obligación. Las reflexiones sobre el contenido posible de las medidas de ajuste cerraron su intervención, y se enfocaron a exponer la amplia variedad admitida (adaptaciones físicas, organizativas, cambio de funciones, permisos específicos, suspensiones, etc.) y la existencia de diversas medidas en nuestro ordenamiento jurídico que podrían operar como ajustes razonables.

El segundo panel, moderado por el prof. Miranda Boto (USC), se inició con la intervención de la prof. Blázquez Agudo (UC3M), cuya exposición se tituló: "Empleo y discapacidad. Un análisis en perspectiva de género". La ponente destacó las diferencias que existen entre el empleo de los hombres y las mujeres, que se ven agravadas cuando existe la condición de persona con discapacidad, y la nula atención que dedica la CIDPD a la perspectiva de género, muy necesaria en esta materia. Desde un punto de vista español, su explicación partió de la especial encomienda a la tutela especial sobre los derechos de las mujeres con discapacidad contenida en el artículo 7.4 de la LGDPCD, reforzando la necesidad de materializar dicha tutela a través de la exposición de distintos datos y cifras que evidencia la existencia de claras desventajas que sufren las mujeres con discapacidad en materia de empleo. A continuación, la ponente detalló el esquema de contratación de las mujeres con discapacidad en el empleo ordinario, en el empleo protegido y el autoempleo, así como sus correspondientes incentivos, finalizando su intervención con la necesidad de tomar medidas y derribar barreras que eliminen las diferencias entre hombres y mujeres con discapacidad en materia de empleo. Entre las propuestas formuladas, la ponente destacó 
la importancia de introducir medidas en la negociación colectiva, adaptar los incentivos al empleo, la promoción del teletrabajo o la puesta en marcha de acciones de sensibilización y prevención de riesgos laborales con perspectiva de género.

La última intervención de la mañana fue a cargo del Ilmo. Sr. Juan Carlos Iturri (Magistrado del Tribunal Superior de Justicia del País Vasco), cuya ponencia se tituló "Despidos no causales de trabajadores en situación de incapacidad temporal". Tras los agradecimientos de rigor, el magistrado efectuó un exhaustivo y completo repaso a la doctrina del Tribunal Supremo y de algunos Tribunales de Justicia en materia de extinción del contrato de trabajo en situaciones de Incapacidad Temporal, cuya calificación legal varió a lo largo de los años de la nulidad a la improcedencia. En este sentido, el ponente destacó cómo la vía del artículo 54.2.e del TRLET (despido disciplinario por disminución continuada y voluntaria del rendimiento) es la más habitual para justificar los despidos de las personas trabajadores en situación de incapacidad temporal y está cuestión fue conectada con una aproximación comparada de la cuestión (Francia y países anglosajones). Desde un punto de vista judicial, el ponente destacó que existen situaciones, ciertamente excepcionales, en las que el Tribunal Supremo ha admitido la nulidad de los despidos de personas trabajadores en situación de incapacidad temporal. La primera sentencia en la que se detuvo el ponente fue la dictada por el Tribunal Supremo el 29 de enero de 2001 (Rec. 1566/2000), en la que se defiende que la enfermedad no es una circunstancia que pueda incardinardinarse en las previstas en el artículo 14 de la Constitución Española dado que no se aprecia un factor de diferenciación que merece especial rechazo por el ordenamiento jurídico, y por lo tanto, la enfermedad no constituye una causa de discriminación y las extinciones fundamentadas en esta circunstancia no pueden motivar la calificación de nulidad. Y, de hecho, el Tribunal Supremo se ha encargado de diferenciar la enfermedad de la discapacidad por el carácter permanente y reconocimiento oficial de la segunda categoría, al amparo de la STS de 11 de diciembre de 2007 (Rec. 4355/2006). No obstante, existen situaciones excepcionales en las que la nulidad será la calificación idónea, y ellas se producirán cuando exista una situación de coacción empresarial para que el trabajador finalice la situación de IT (STS de 31 de enero de 2011, Rec. 1532/2010).

El tercer y último panel, moderado por el prof. Pérez del Prado (UC3M), se inició con la ponencia del prof. Gutiérrez Colominas (UAB), titulada: "Cuota de empleo de personas con discapacidad y medidas alternativas". En su intervención, el profesor Gutiérrez presentó las discordancias que presenta la actual configuración legal de la cuota de reserva de empleo con la CIDPD. Para ello, abordó el actual marco jurídico aplicable a esta institución, con una especial consideración a la CIDPD, y poniendo de manifiesto la incompatibilidad de la configuración actual de la cuota de empleo de las personas con discapacidad, concretada en el artículo 42 de la LGDPCD, el Real Decreto 364/2005, de 8 de abril, por el que se regula el cumplimiento alternativo con carácter excepcional de la cuota de reserva en favor de los trabajadores con discapacidad y el criterio técnico 98/2016 sobre actuaciones de la inspección de trabajo y seguridad social en materia de cuota de reserva de puestos de trabajo para personas con discapacidad. En particular, la tesis del profesor Gutiérrez pivotó en torno a las disfunciones que presenta el ámbito subjetivo (concepto 
de trabajador con discapacidad a efectos del cumplimiento de la cuota) y objetivo (falta de conexión con otros mecanismos de integración laboral que constituyen la materialización del modelo social), presentando propuestas de mejora de la actual configuración para lograr la plena compatibilidad de la institución con la CIDPD.

La última intervención de las jornadas se realizó a cargo de la prof. Moreno Solana (UC3M), que abordó la extinción del contrato de trabajo vinculada a la discapacidad. Concretamente, la ponente contextualizó su exposición en la extinción derivada de incapacidad permanente (art. 49.1.e TRLET), la extinción objetiva por ineptitud sobrevenida del trabajador (art. 52.a TRLET) y la extinción por faltas de asistencia, aún justificadas, del trabajador (art. 52.d TRLET), clarificando aquellas zonas grises entre la incapacidad permanente y la ineptitud sobrevenida con la discapacidad, y la especial incidencia de las ausencias, aún justificadas, por razones médicas en trabajadores con discapacidad. De forma más precisa, la profesora Moreno inició su intervención excluyendo la Incapacidad Permanente Parcial de la ecuación, toda vez que no da lugar a la extinción automática de la relación y centrando la discusión en torno a la evolución y actual configuración de la asimilación de la situación de incapacidad permanente a la discapacidad, resuelta recientemente en las STS de 29 de noviembre de 2018 (Rec. 1826/2017 y 3382/2016). Su exposición continuó con el examen la frontera entre la discapacidad y la ineptitud sobrevenida, destacando el papel de las medidas preventivas como consecuencia de la STS de 22 de febrero de 2018 (Rec. 160/2016), y haciendo especial mención a la diferenciación entre trabajador especialmente sensible y trabajador con discapacidad, especialmente a propósito de la STJUE de 11 de septiembre de 2019, C-397/18, EU:C:2019:703. Por último, la ponente abordó la extinción por faltas de asistencia aún justificadas pero intermitentes (art. 52.d TRLET), exponiendo el actual régimen legal y la estrecha conexión que presenta con la discapacidad en aquellos supuestos en los que las ausencias están conectadas con la situación que genera la discapacidad, tomando como referencia la STJUE de 18 de enero de 2018, C-270/16, EU:C:2018:17, y aprovechando la ocasión para comentar y reflexionar a propósito de la reciente STC de 16 de octubre de 2019 (Rec. 2960/2019) y sus votos particulares.

La jornada finalizó con unas palabras de clausura pronunciadas por el Prof. Miranda Boto, que actúo en calidad de Secretario General de la AEDTSS, felicitando tanto a los/as ponentes como a las personas asistentes al acto. 